EGU21-1545

https://doi.org/10.5194/egusphere-egu21-1545

EGU General Assembly 2021

(c) Author(s) 2022. This work is distributed under

the Creative Commons Attribution 4.0 License.

\title{
3D tomographic imaging of the Cayman Trough lithosphere: challenges, ongoing work and first results
}

\author{
Laura Gómez de la Peña ${ }^{1}$, Ingo Grevemeyer ${ }^{1}$, Anke Dannowsky ${ }^{1}$, Adrià Meléndez ${ }^{2}$, Christine \\ Peirce ${ }^{3}$, and Harm van Avendonk ${ }^{4}$ \\ ${ }^{1}$ GEOMAR Helmholtz Centre for Ocean Research Kiel, Dynamics of the Ocean Floor, Kiel, Germany (Igomez@geomar.de) \\ ${ }^{2}$ Barcelona-CSI, Institute of Marine Sciences, CSIC, Barcelona, Spain \\ ${ }^{3}$ Department of Earth Sciences Durham University, England \\ ${ }^{4}$ University of Texas Institute for Geophysics, Austin, USA
}

About $25 \%$ of the Earth's mid-ocean ridges spread at ultraslow rates of less than $20 \mathrm{~mm} / \mathrm{yr}$. However, most of these ultraslow spreading ridges are located in geographically remote areas, which hamper investigation. Consequently, how the crust forms and ages at such spreading centres, which traditional models predict to be magma-starved and cold, remains poorly understood.

CAYSEIS project was proposed to survey the Cayman Trough area in order to obtain new data that constraints the nature of the crust, tectonic structures, lithologies outcropping and hydrothermal processes taking place in this area, which includes the Mid Cayman ultra-slow spreading centre (MSCS) with spreading rates of $\sim 15-17 \mathrm{~mm} / \mathrm{yr}$. Understanding the sub-seabed geophysical structure of the MCSC is key to understanding not only the lithologies and structures exposed at the seabed, but more fundamentally, how they are related at depth and what role hydrothermal fluid flow plays in the geodynamics of ultraslow spreading. CAYSEIS was a joint and multidisciplinary programme of German, British and US American top tier scientists designed for the obtaining of a new high-quality dataset, including 3D Wide-Angle Seismic (WAS), magnetic, gravimetric and seismological data.

We took leverage of the CAYSEIS dataset to invert a 3D velocity model of the Cayman Trough lithosphere using the Tomo3D code (Meléndez et al., 2015; 2019). This is one of the first times that the Tomo3D code is used for 3D inversion of real datasets. Thus, we are checking our results comparing them with travel time tomographic inversions of 2D lines and testing the different parameters to obtain the more accurate and higher resolution model as possible. The results of this experiment show not only the lithospheric structure along and across the MSCS, including the exhumed Ocean Core Complexes in the surrounding areas, but the 3D lithospheric configuration of the region which is important to understand the crustal formation processes and evolution of ultra-slow spreading settings. 